\title{
Delay in Diagnosis of Hemoglobulinopathies (Thalassemia, Sickle Cell Anemia): A Need for Management of Thalassemia Programs
}

\author{
Jafar Hassanzadeh, ${ }^{1}$ Alireza Mirahmadizadeh, ${ }^{2}$ Mehran Karimi, ${ }^{3}$ and Shahab Rezaeian ${ }^{4,}$ \\ ${ }^{1}$ Research Centre for Health Sciences, Department of Epidemiology, School of Health, Shiraz University of Medical Sciences, Shiraz, IR Iran \\ ${ }^{2}$ Department of Epidemiology, School of Health, Non-Communicable Diseases Research Center, Shiraz University of Medical Sciences, Shiraz, IR Iran \\ ${ }^{3}$ Hematology Research Center, Shiraz University of Medical Sciences, Shiraz, IR Iran \\ ${ }^{4}$ Department of Epidemiology, School of Health, Shiraz University of Medical Sciences, Shiraz, IR Iran \\ "Corresponding author: Shahab Rezaeian, MSc, PhD Candidate, Department of Epidemiology, School of Health, Shiraz University of Medical Sciences, P.O. Box 71645-111, Shiraz, \\ IR Iran. Tel: +98-9189814634, Fax: +98-7137260225, E-mail: shahab.rezayan@gmail.com
}

Received 2016 May 05; Revised 2016 August 19; Accepted 2016 October 20.

\begin{abstract}
Background: Hemoglobulinopathies (Thalassemia, Sickle cell anemia) are an important public health challenge worldwide with an estimated number of 330,000 affected newborns annually. Delay in diagnosis not only increases the morbidity and mortality rates, but also can lead to uncertainties about success of thalassemia prevention program (TPP). This study is the first to determine the delay in thalassemia diagnosis in Iranian population.

Methods: This registry-based cross-sectional study was conducted on 1003 enrolled thalassemic patients in 2015 in Shiraz, Iran. Univariate and multivariate ordinal logistic regression models were used to assess the factors associated with delay in diagnosis.

Results: Of 981 patients, $48.5 \%$ were female, $71.2 \%$ were thalassemia major, and $23.8 \%$ were death cases. The delay in diagnosis was observed among $64.9 \%$ of the patients with a mean of 13.4 months (95\% CI:10.9,15.9). Multivariate ordinal logistic regression showed that girls (adjusted $O R=1.32$ ), and dead patients (adjusted $O R=1.95$ ) were more likely to have delayed diagnosis. There was an increasing trend of risk in delayed diagnosis associated with one-year per birth cohort. The ORs were 1.0, 1.52, 1.55, and 2.22, for birth cohort 1980 and earlier, 1981 - 1990, 1991 - 2000, and 2001 to the present, respectively (P for trend $=0.014$ ). In addition, the odds of delayed diagnosis in thalassemia major patients were significantly 0.58 times lower than those with thalassemia intermedia.

Conclusions: A high proportion of delayed diagnosis was found. These results could explain the poor outcomes for thalassemia patients. Educational programs for community and revising the TPP are required for early detection of the disease.
\end{abstract}

Keywords: Delayed Diagnosis, Thalassemia, Sickle Cell Anemia, Iran

\section{Background}

Thalassemia disease is an important public health challenge in both developed and developing countries with an estimated number of 330,000 affected newborns annually $(1,2)$. It is markedly more prevalent in Middle Eastern countries such as Iran, which is geographically located in the "thalassemia belt".

Nation-wide and local epidemiologic studies on the disease conducted in Iran have provided powerful data about the disease and health care system. The findings of a review study show the success of thalassemia prevention program (TPP) in the reduction of new thalassemia births (3). Another study supported the functionality of the prevention program (4). In addition, some studies have reported a significant improvement in treatment (5) and the quality of life in patients (6), decreasing mortality (7), and improving the survival rate (8). Notwithstanding the mentioned issues, it is estimated that over 300 new cases are born every year (9).

Previous studies on other diseases have shown that de- lay in diagnosis, or treatment, would result in worsening of the prognosis and the survival rate (10-12). On the other hand, delay in diagnosis is associated with more advanced disease requiring more advanced treatment. This leads to increased morbidity and decreased survival. Thalassemia is an inherited hemoglobin disorder which can be recognized by prenatal testing (13). There is no published study from Iran or other countries on the delay in diagnosis or treatment of thalassemia patients. Therefore, this study is the first to gain insight into delay in thalassemia diagnosis to improve prognosis of the disease in this population.

\section{Methods}

\subsection{Study Setting and Patients}

This registry-based cross-sectional study was conducted on 1003 beta-thalassemia (major, intermedia), or sickle cell patients in 2015 in Shiraz, the capital city in southern province of Iran. The study was approved by the ethics review committee and supported by a grant (No. 94-7610) from Shiraz University of Medical Sciences. 


\subsection{Thalassemia Prevention Program in Iran}

The pilot TPP was initiated in 1991 and established throughout the country in 1997 (14). This program consists of three stages: The first stage screens couples prior to marriage, second stage screens families of thalassemic patients, and the last one screens carrier couples who had married prior to 1997. Moreover, prenatal diagnosis (PND) was a main element of this program (14). Although this program helps the disease be detected before birth, many new cases of thalassemia are still born annually (13).

\subsection{Instruments}

The patients with thalassemia receiving regular blood transfusions were prospectively tracked by a referral hospital in Shiraz. Data collection was carried out using a checklist including date of birth, date of death (if applicable), sex, type of thalassemia (major, intermedia) or sickle cell, education level and occupation of the parents. Date of birth was defined as birth cohort and was divided into four birth cohorts (1980 and earlier, 1981 - 1990, 1991 - 2000, and 2001 to the present). The birth cohort of 1980 and before was considered to be the reference group. The Patients with missing data or those who had no medical record were excluded from the study. Delayed diagnosis was defined as the time between birth date and the date of final hematological (electrophoresis) diagnosis. It was divided in three categories of no delay, delay less than 12 months, and delay more than 12 months.

\subsection{Statistical Analysis}

Descriptive analyses were used to calculate means, frequencies and percentages. T-test and one-way ANOVA were used to compare the delay mean between the groups. To assess the factors associated with delay, univariate and multivariate ordinal logistic regression models were used, and unadjusted and adjusted odds ratios (OR) were determined within $95 \%$ confidence intervals (95\% CI). All statistical analyses were performed at 0.05 significance level using Stata 11 (StataCorp, College Station, TX, USA).

\section{Results}

Overall, 1003 thalassemia patients were registered in the referral hospital. Of these, 22 subjects (17 from alive and 5 from deceased patients) were excluded due to missing data (Response rate $=97.8 \%$ ). Of the 981 patients, $48.5 \%$ were female, $71.2 \%$ had thalassemia major, and $23.8 \%$ were death cases. The delay in diagnosis was observed in $64.9 \%$ of the patients with a mean of 13.4 months (95\% CI: 10.9, 15.9).
The additional descriptive statistics of the thalassemia patients based on categories of delay in diagnosis are shown in Table 1.

Table 2 shows unadjusted and adjusted associations between the delay in diagnosis and some independent factors. In bivariate analysis, delayed diagnosis was associated with gender, maternal education, type of thalassemia, birth cohort, and patient's status.

In multivariate ordinal logistic regression, our findings showed that girls were more likely to have delayed diagnosis compared to boys (adjusted OR $=1.32,95 \% \mathrm{CI}$ : $1.02,1.71)$. The odds of delayed diagnosis in thalassemia major patients were significantly 0.58 times lower than in those with thalassemia intermedia. There was an increasing trend of risk in delayed diagnosis associated with oneyear per birth cohort, the ORs were 1.0, 1.52, 1.55, and 2.22, respectively for birth cohort 1980 and before, 1981 - 1990, $1991-2000$, and 2001 to the present ( $P$ for trend $=0.014$ ). Deceased patients were 1.95 times more likely to have the delayed diagnosis compared to alive patients.

No statistically significant associations were observed between delayed diagnosis and maternal education and occupation, and father's education.

\section{Discussion}

Our results show that thalassemia patients are facing an important challenge in terms of diagnosis delay. The main goals of TPP are early diagnosis of thalassemia and prevention of new cases. Despite significant improvements in the TPP in Iran, the rate of delay in diagnosis must be considered by policymakers to modify the program. Assessing factors associated with diagnosis delay might be an important way to identify how to improve the quality of thalassemia program. Accordingly, the results of our study can help policymakers in this purpose.

After the establishment of TPP in Iran, the program has been evaluated from different perspectives. The first study conducted by Samavat et al. (14) in 2004, and another one in 2007 (15) showed a significant success in decreasing the rate of thalassemia newborns, which was further validated by other studies (16-18). Khorasani et al. (16) in a study to evaluate the success of the program concluded that the TPP has significantly reduced the financial burden upon thalassemic patients and their families. On the other hand, some other studies have reported program weaknesses. Findings of a study to evaluate the Iranian TPP during 20072009 revealed that the program should be revised in at-risk provinces especially in Sistan-Baluchestan and Kohkiluyeh Boyer-Ahmad (19). In addition, the delay in registration of thalassemic patients in the disease registration system as a limitation of the program has been pointed in previous 
Hassanzadeh J et al.

Table 1. Descriptive Statistics of the Thalassemia Patients Based on Categories of Delay in Diagnosis

\begin{tabular}{|c|c|c|c|c|c|c|}
\hline & \multirow[t]{2}{*}{ Category } & \multicolumn{3}{|c|}{ Delay in Diagnosis } & \multirow[t]{2}{*}{ Mean $(95 \% \mathrm{CI})$} & \multirow[t]{2}{*}{ P Value } \\
\hline & & No Delay & $\leq 12$ Months & > 12 Months & & \\
\hline \multirow{2}{*}{ Gender } & Male & $184(36.4)$ & $221(43.8)$ & $100(19.8)$ & $10.9(8.1,13.7)$ & \multirow{2}{*}{0.042} \\
\hline & Female & $160(33.6)$ & $185(38.9)$ & $131(27.5)$ & $16.0(11.9,20.2)$ & \\
\hline \multirow{2}{*}{ Type of hemoglobulinopathy } & Thalassemia intermedia & $99(37.2)$ & $36(13.5)$ & $131(49.3)$ & $23.3(17.1,28.8)$ & \multirow{2}{*}{$<0.001$} \\
\hline & Sickle cell & $6(37.5)$ & $6(37.5)$ & $4(25.0)$ & - & \\
\hline \multirow{4}{*}{ Mother's education } & Illiterate & $58(29.1)$ & $84(42.2)$ & $57(28.7)$ & $12.0(9.8,14.3)$ & \multirow{4}{*}{0.001} \\
\hline & Primary school & $161(33.3)$ & $188(38.9)$ & $134(27.8)$ & $15.2(11.8,18.6)$ & \\
\hline & Secondary school & $56(39.2)$ & $64(44.8)$ & $23(16.0)$ & $9.0(6.7,11.4)$ & \\
\hline & Academic & $14(30.4)$ & $21(45.7)$ & $11(23.9)$ & $36.5(0.1,73.0)$ & \\
\hline \multirow{2}{*}{ Mother's job } & Housekeeper & $273(34.7)$ & $331(42.1)$ & $182(23.2)$ & $12.8(10.6,15.0)$ & \multirow{2}{*}{$<0.001$} \\
\hline & Employed & $15(31.2)$ & $15(31.2)$ & $18(37.6)$ & $38.0(2.4,73.6)$ & \\
\hline \multirow{4}{*}{ Father's education } & Illiterate & $43(31.9)$ & $51(37.8)$ & $41(30.3)$ & $13.4(10.4,16.4)$ & \multirow{4}{*}{0.199} \\
\hline & Primary school & $145(32.0)$ & $185(40.8)$ & $123(27.2)$ & $13.9(11.6,16.1)$ & \\
\hline & Secondary school & $64(35.0)$ & $81(44.3)$ & $38(20.7)$ & $12.7(5.6,19.8)$ & \\
\hline & Academic & $37(36.6)$ & $41(40.6)$ & $23(22.8)$ & $22.9(6.0,39.9)$ & \\
\hline \multirow{4}{*}{ Birth cohort } & 1980 and earlier & $55(45.5)$ & $41(33.9)$ & $25(20.7)$ & $23.6(6.3,40.9)$ & \multirow{4}{*}{0.016} \\
\hline & $1981-1990$ & $157(34.0)$ & $191(41.3)$ & $114(24.7)$ & $13.3(11.0,15.7)$ & \\
\hline & $1991-2000$ & $105(36.0)$ & $123(42.1)$ & $64(21.9)$ & $10.3(8.6,12.0)$ & \\
\hline & 2001 to present & $26(26.0)$ & $47(47.0)$ & $27(27.0)$ & $10.7(8.5,12.9)$ & \\
\hline Patient's status & Alive & $271(36.3)$ & $312(41.8)$ & $164(21.9)$ & $11.8(9.7,13.9)$ & 0.021 \\
\hline Total & - & $344(35.1)$ & $406(41.4)$ & $231(23.5)$ & $13.4(10.9,15.9)$ & - \\
\hline
\end{tabular}

studies $(9,17)$. Nevertheless, no similar study was found on the delayed diagnosis in thalassemia in Iran or other countries. As far as we know, this is the first study in this regard worldwide. On the other hand, we suppose that policymakers probably think that the diagnosis testing such as PND can detect all of the disease cases. However, there are numerous patient- and health system-related factors associated with the delay in diagnosis.

We found that $64.9 \%$ of patients had delayed diagnosis. The high proportion (41.4\%) of them had delay less than 12 months. On the other hand, this time, i.e. 12 months after birth, is the time for immunization of children. It, therefore, is concurrent with the immunization program which was launched in Iran in 1984 (20). This issue could explain the shorter mean delay in the birth cohort of 1981 - 1990, 1991 -2000, and 2001 to the present compared to the birth cohort of 1980 and before. Despite a significant decrease in the mean delay, ordinal logistic regression showed a positive linear trend in birth cohorts which was associated with delay in diagnosis. This finding suggests that there is still a major problem in the TPP.

Based on both unadjusted and adjusted ordinal logistic models, sex was an important predictor of delayed diagnosis in the patients. Gender disparity in healthcare utilization and health related factors have been widely reported (21-23). In some societies, for example India, gender discrimination is an important determinant of healthcare utilization such as childhood vaccination (21). Our study revealed that the odds of delayed diagnosis were greater in girls than boys. They also had a higher mean delay compared to boys (16.0 vs. 10.9 months, P value $=0.042$, respectively). Also in a few studies, significant gender-based differences of delay have been reported in presentation of childhood disorders $(24,25)$.

The risk of delayed diagnosis in thalassemic patients was lower among high educated parents. Some ways could be noticed that infant health is associated with the level of parental education. For example, Wehby et al. reported 
Table 2. Unadjusted and Adjusted Odds Ratios and 95\% Confidence Interval From Ordinal Logistic Regression Based on the Delay in Diagnosis in Thalassemia Patients

\begin{tabular}{|c|c|c|c|c|c|}
\hline & Category & $\begin{array}{l}\text { Unadjusted } \\
\text { OR(95\% CI) }\end{array}$ & P Value & $\begin{array}{l}\text { Adjusted }^{\mathrm{a}} \\
\text { OR(95\% CI) }\end{array}$ & P Value \\
\hline \multirow{2}{*}{ Gender } & Male & Reference & - & Reference & - \\
\hline & Female & $1.28(1.01,1.61)$ & 0.037 & $1.32(1.02,1.71)$ & 0.034 \\
\hline \multirow{3}{*}{ Type of hemoglobulinopathy } & $\begin{array}{c}\text { Thalasemmia } \\
\text { intermedia }\end{array}$ & Reference & - & Reference & - \\
\hline & Thalasemmia major & $0.43(0.32,0.57)$ & 0.001 & $0.42(0.30,0.57)$ & $<0.001$ \\
\hline & Sickle cell & $0.50(0.19,1.31)$ & 0.159 & $0.89(0.31,2.76)$ & 0.884 \\
\hline \multirow{5}{*}{ Mother's education } & Illiterate & Reference & - & Reference & - \\
\hline & Primary school & $0.88(0.65,1.20)$ & 0.421 & $0.89(0.61,1.28)$ & 0.530 \\
\hline & Secondary school & $0.60(0.40,0.90)$ & 0.009 & $0.63(0.38,1.05)$ & 0.079 \\
\hline & Academic & $0.87(0.50,1.56)$ & 0.637 & $0.93(0.43,2.03)$ & 0.867 \\
\hline & Trend & $0.85(0.73,0.99)$ & 0.045 & $0.88(0.71,1.10)$ & 0.246 \\
\hline \multirow{2}{*}{ Mother's job } & Housekeeper & Reference & & Reference & - \\
\hline & Employed & $1.56(0.89,2.73)$ & 0.119 & $1.21(0.65,2.24)$ & 0.540 \\
\hline \multirow{5}{*}{ Father's education } & Illiterate & Reference & - & Reference & - \\
\hline & Primary school & $0.92(0.64,1.32)$ & 0.658 & $1.03(0.67,1.58)$ & 0.905 \\
\hline & Secondary school & $0.74(0.49,1.12)$ & 0.156 & $0.98(0.58,1.66)$ & 0.951 \\
\hline & Academic & $0.74(0.46,1.20)$ & 0.222 & $1.03(0.54,1.96)$ & 0.923 \\
\hline & Trend & $0.88(0.77,1.02)$ & 0.089 & $0.99(0.82,1.21)$ & 0.969 \\
\hline \multirow{5}{*}{ Birth cohort } & 1980 and earlier & Reference & - & Reference & - \\
\hline & $1981-1990$ & $1.50(1.03,2.19)$ & 0.036 & $1.52(0.97,2.36)$ & 0.066 \\
\hline & $1991-2000$ & $1.34(0.90,2.00)$ & 0.150 & $1.55(0.97,2.47)$ & 0.066 \\
\hline & 2001 to present & $1.93(1.18,3.17)$ & 0.009 & $2.22(1.28,3.85)$ & 0.005 \\
\hline & Trend & $1.14(0.99,1.31)$ & 0.070 & $1.22(1.04,1.42)$ & 0.014 \\
\hline \multirow{2}{*}{ Patient's status } & Alive & Reference & - & Reference & - \\
\hline & Dead & $1.33(1.01,1.75)$ & 0.041 & $1.95(1.33,2.85)$ & 0.001 \\
\hline
\end{tabular}

Abbreviations: OR, odds ratio; $\mathrm{CI}$, confidence interval.

${ }^{\text {a } A d j u s t e d ~ f o r ~ a l l ~ o t h e r ~ v a r i a b l e s ~ l i s t e d ~ i n ~ t h e ~ t a b l e . ~}$

that the higher parental education increased the number of prenatal care visits and decreased the risk of preterm birth (26). Numerous previous studies have also reported a significant relationship between maternal education and infant health $(27,28)$. Accordingly, since high maternal education is an important predictor of child health, expanding the health educational programs are required to improve health literacy and health knowledge of mothers. In our study, the mean delay was significantly higher among those patients who had employed mother, and ordinal logistic regression also showed a higher odds of delayed diagnosis among employed mothers than unemployed ones, but without significance. Maternal occupation may affect infant health that was also considered in several studies
(29, 30). Time, for example maternal time for receiving healthcare, is an important factor to determine well-baby care receipt (31).

\subsection{Study Limitations and Strengths}

This study encountered some limitations. First, we performed a retrospective cross-sectional study and used data recorded by the registry center. Hence, we were unable to assess the quality of the recorded data. This might raise information bias. On the other hand, there are probably other factors associated with patients and healthcare system delay that could not be assessed in this study. The main strength is its novelty in reporting of delay in diagnosis 
with an appropriate sample size from a developing country. It may help policymakers who plan preventive programs reduce thalassemia rate.

\subsection{Conclusions}

A high proportion of delayed diagnosis was found. These results could explain the poor outcomes for thalassemia patients. We suggest that the PND errors and the causes of delayed diagnosis be recorded and analyzed. Educational programs for the community and revising the thalassemia prevention program are required for early detection of the disease.

\section{Acknowledgments}

The present paper was extracted from the PhD thesis by Shahab Rezaeian and was financially supported by Shiraz University of Medical Sciences (grant No. 94-7610). The authors would like to thank all staff of Shahid Dastgheib hospital.

\section{References}

1. Modell B, Darlison M. Global epidemiology of haemoglobin disorders and derived service indicators. Bull World Health Organ. 2008;86(6):480-7. [PubMed: 18568278].

2. Weatherall DJ, Clegg JB. Inherited haemoglobin disorders: an increasing global health problem. Bull World Health Organ. 2001;79(8):704-12. [PubMed: 11545326].

3. Hashemieh M, Timori Naghadeh $\mathrm{H}$, Tabrizi Namini M, Neamatzadeh H, Hadipour Dehshal M. The Iran Thalassemia Prevention Program: Success or Failure?. Iran JPed Hematol Oncol. 2015;5(3):161-6. [PubMed: 26705456].

4. Najmabadi H, Ghamari A, Sahebjam F, Kariminejad R, Hadavi $\mathrm{V}$, Khatibi T, et al. Fourteen-year experience of prenatal diagnosis of thalassemia in Iran. Community Genet. 2006;9(2):93-7. doi: 10.1159/000091486. [PubMed: 16612059].

5. Keikhaei B, Yousefi H, Bahadoram M. Clinical and Haematological Effects of Hydroxyurea in beta-Thalassemia Intermedia Patients. $J$ Clin Diagn Res. 2015;9(10):OM01-3. doi:10.7860/JCDR/2015/14807.6660. [PubMed: 26557561].

6. Kaheni S, Yaghobian M, Sharefzadah GH, Vahidi A, Ghorbani H, Abderahemi A. Quality of life in children with beta-thalassemia major at center for special diseases. Iran J Ped Hematol Oncol. 2013;3(3):108-13. [PubMed: 24575281].

7. Rezaei N, Naderimagham S, Ghasemian A, Saeedi Moghaddam S, Gohari K, Zareiy S, et al. Burden of Hemoglobinopathies (Thalassemia, Sickle Cell Disorders and G6PD Deficiency) in Iran, 1990-2010: findings from the Global Burden of Disease Study 2010. Arch Iran Med. 2015;18(8):502-7. [PubMed: 26265518].

8. Zamani R, Khazaei S, Rezaeian S. Survival analysis and its associated factors of Beta thalassemia major in hamadan province. Iran J Med Sci. 2015;40(3):233-9. [PubMed: 25999623].

9. Dehshal MH, Ahmadvand A, Darestani SY, Manshadi M, Abolghasemi $H$. Secular trends in the national and provincial births of new thalassemia cases in Iran from 2001 to 2006. Hemoglobin. 2013;37(2):12437. doi: 10.3109/03630269.2013.772062. [PubMed: 23470148].

10. Abu-Helalah MA, Alshraideh HA, Da'na M, Al-Hanaqtah M, Abuseif A, Arqoob K, et al. Delay in Presentation, Diagnosis and Treatment for Colorectal Cancer Patients in Jordan. J Gastrointest Cancer. 2016;47(1):36-46. doi: 10.1007/s12029-015-9783-3. [PubMed: 26615546].
11. Neal RD, Tharmanathan P, France B, Din NU, Cotton S, Fallon-Ferguson $\mathrm{J}$, et al. Is increased time to diagnosis and treatment in symptomatic cancer associated with poorer outcomes? Systematic review. $\mathrm{Br} J$ Cancer. 2015;112 Suppl 1:S92-107. doi: 10.1038/bjc.2015.48. [PubMed: 25734382].

12. Huo Q, Cai C, Zhang Y, Kong X, Jiang L, Ma T, et al. Delay in diagnosis and treatment of symptomatic breast cancer in China.Ann Surg Oncol. 2015;22(3):883-8. doi: 10.1245/s10434-014-4076-9. [PubMed: 25212834].

13. Moradi G, Ghaderi E. Chronic disease program in Iran: Thalassemia control program. Chron Dis J. 2013;1(2):98-106.

14. Samavat A, Modell B. Iranian national thalassaemia screening programme. BMJ. 2004;329(7475):1134-7. doi: 10.1136/bmj.329.7475.1134. [PubMed: 15539666].

15. Abolghasemi H, Amid A, Zeinali S, Radfar MH, Eshghi P, Rahiminejad MS, et al. Thalassemia in Iran: epidemiology, prevention, and management. J Pediatr Hematol Oncol. 2007;29(4):233-8. doi: 10.1097/MPH.0b013e3180437e02. [PubMed: 17414565].

16. Khorasani G, Kosaryan M, Vahidshahi K, Shakeri S, Nasehi MM. Results of the national program for prevention of beta-thalassemia major in the Iranian Province of Mazandaran. Hemoglobin. 2008;32(3):263-71. doi: 10.1080/03630260802004269. [PubMed: 18473242].

17. Miri M, Tabrizi Namini M, Hadipour Dehshal M, Sadeghian Varnosfaderani F, Ahmadvand A, Yousefi Darestani S, et al. Thalassemia in Iran in last twenty years: the carrier rates and the births trend. Iran J Blood Cancer. 2013;6(1):11-7.

18. Nikuei P, Hadavi V, Rajaei M, Saberi M, Hajizade F, Najmabadi H. Prenatal diagnosis for beta-thalassemia major in the Iranian Province of Hormozgan. Hemoglobin. 2008;32(6):539-45. doi: 10.1080/03630260802508327. [PubMed:19065331].

19. Hadipour Dehshal M, Tabrizi Namini M, Ahmadvand A, Manshadi M, Sadeghian Varnosfaderani F, Abolghasemi H. Evaluation of the national prevention program in iran, 2007-2009: the accomplishments and challenges with reflections on the path ahead. Hemoglobin. 2014;38(3):179-87. doi: 10.3109/03630269.2014.893530. [PubMed: 24669933].

20. Zahraei SM, Marandi A, Sadrizadeh B, Gouya MM, Rezaei P, Vazirian $P$, et al. Role of National Immunization Technical Advisory Group on improvement of immunization programmes in the Islamic Republic of Iran. Vaccine. 2010;28 Suppl 1:A35-8. doi: 10.1016/j.vaccine.2010.02.030. [PubMed: 20412994].

21. Prusty RK, Kumar A. Socioeconomic dynamics of gender disparity in childhood immunization in India, 1992-2006. PLoS One. 2014;9(8):e104598. doi: 10.1371/journal.pone.0104598. [PubMed: 25127396].

22. Khera R, Jain S, Lodha R, Ramakrishnan S. Gender bias in child care and child health: global patterns. Arch Dis Child. 2014;99(4):369-74. doi: 10.1136/archdischild-2013-303889. [PubMed: 24344176].

23. Hassanzadeh J, Moradi N, Esmailnasab N, Rezaeian S, Bagheri P, Armanmehr $\mathrm{V}$. The correlation between gender inequalities and their health related factors in world countries: a global cross-sectional study. Epidemiol Res Int. 2014;2014.

24. Chaudhry TA, Khan A, Khan MB, Ahmad K. Gender differences and delay in presentation of childhood squint. J Pak Med Assoc. 2009;59(4):229-31. [PubMed: 19402285].

25. Tveitnes D, Oymar K. Gender Differences in Childhood Lyme Neuroborreliosis. Behav Neurol. 2015;2015:790762. doi: 10.1155/2015/790762. [PubMed: 26576072].

26. Wehby GL, Murray JC, Castilla EE, Lopez-Camelo JS, Ohsfeldt RL. Prenatal care effectiveness and utilization in Brazil. Health Policy Plan. 2009;24(3):175-88. doi: 10.1093/heapol/czp005. [PubMed: 19282483].

27. Quansah E, Ohene LA, Norman L, Mireku MO, Karikari TK. Social Factors Influencing Child Health in Ghana. PLoS One. 2016;11(1):e0145401. doi: 10.1371/journal.pone.0145401. [PubMed: 26745277]. 
28. Nyarko KA, Lopez-Camelo J, Castilla EE, Wehby GL. Explaining racial disparities in infant health in Brazil. Am J Public Health. 2013;103(9):1675-84. doi: 10.2105/AJPH.2012.301021. [PubMed: 23409894].

29. von Ehrenstein OS, Wilhelm M, Wang A, Ritz B. Preterm birth and prenatal maternal occupation: the role of Hispanic ethnicity and nativity in a population-based sample in Los Angeles, California. Am J Public Health. 2014;104 Suppl 1:S65-72. doi: 10.2105/AJPH.2013.301457. [PubMed: 24354840].
30. Casas M, Cordier S, Martinez D, Barros H, Bonde JP, Burdorf A, et al. Maternal occupation during pregnancy, birth weight, and length of gestation: combined analysis of 13 European birth cohorts. Scand J Work Environ Health. 2015;41(4):384-96. doi: 10.5271/sjweh.3500. [PubMed: 25940455].

31. Hamman MK. Making time for well-baby care: the role of maternal employment. Matern Child Health J. 2011;15(7):1029-36. doi: 10.1007/s10995-010-0657-9. [PubMed: 20706867]. 